\title{
EDITORIAL
}

\section{Persistent Pulmonary Hypertension of Newborn (PPHN)}

\author{
Manzoor Hussain
}

\section{Introduction}

Persistent pulmonary hypertension of the newborn (PPHN) can occur due to failure of the normal cardiopulmonary transition. Incidence is 2 per 1000 live born term infants, and some degree of pulmonary hypertension complicates the course of more than $10 \%$ of all neonates with respiratory failure. ${ }^{1}$ It is associated with high mortality and morbidity.

Pulmonary hypertension is a normal and necessary state for the fetus. At birth, with air entering the lungs and the umbilical cord being clamped, the situation is reversed with the Pulmonary vascular resistance (PVR) falling due to vasodilatation of vessels with oxygenation and systemic vascular resistance (SVR) rising due to the elimination of the low-resistance placental circuit. In PPHN this transition is disturbed, resulting in sustained elevation of PVR. PVR exceeds SVR resulting in the right-to-left haemodynamic shunting through the patent foramen ovale and/or ductus arteriosus leading to the vicious cycle of hypoxaemia, further resulting in pulmonary vasoconstriction leading to diminishing pulmonary perfusion and systemic hypoxaemia. ${ }^{2}$ The main hallmarks of PPHN include sustained elevation of PVR, abnormal vasoreactivity and structural remodeling of the pulmonary vascular bed. ${ }^{3}$ Idiopathic PH is found in $10-20 \%$ of all infants with PPHN. ${ }^{4}$

A high index of clinical suspicion is warranted to diagnose PPHN in a baby. The presence of any of the risk factors like Birth asphyxia, Meconium aspiration, Early-onset Sepsis/Pneumonia, Pulmonary hypoplasia due to causes like Congenital diaphragmatic hernia, amniotic fluid leak, oligohydramnios, pleural effusion, maternal drug intake like NSAIDs (Ibuprofen, aspirin, naproxen, indomethacin) and selective serotonin-reuptack (SSRI), especially fluoxetine, other factors like RDS, hypothermia, hypoglycaemia, polycythaemia, familial occurrence should prompt the diagnosis. ${ }^{5,6}$

\section{Diagnosis}

Affected infants are usually full-term or post-term and are frequently born through meconium-stained amniotic fluid. The infant is either ill in the delivery room itself or illness manifests within the first 12 hours of life. Infants with PPHN may manifest with severe cyanosis, tachypnoea, grunting, nasal flaring, chest retractions, tachycardia, and shock although signs of respiratory distress may be minimal initially. ${ }^{7}$ Cardiac examination may reveal prominent precordial impulse, single or narrowly split and accentuated second heart sound and/or a systolic murmur consistent with tricuspid valve regurgitation. Heart failure is usually not seen though hypotension is encountered. ${ }^{7}$ Difference in pre and post ductal saturation of $>10 \%$ in the absence of structural heart disease suggests PPHN. ${ }^{8}$ When hyperventilated for 10 minutes, infants with PPHN may show an increase in $\mathrm{PaO}_{2}$ by $>30 \mathrm{mmHg}$ when $\mathrm{pH}$ is raised to $7.55 .{ }^{9}$ The chest radiograph usually appears normal in asphyxia associated and idiopathic PPHN. Echocardiography remains the gold standard for diagnosing PPHN. Differential diagnosis include cyanotic congenital heart disease (especially obstructed total anomalous pulmonary venous connection) and entities that predispose to PPHN. ${ }^{10}$

\section{Management}

The aim of treatment is to lower pulmonary vascular resistance, maintain systemic blood pressure, reverse right to left shunt, and improve arterial oxygen saturation. ${ }^{11}$ For the majority of PPHN

Former Head of Paediatric Medicine and Cardiology, Bangladesh Institute of Child Health and Dhaka Shishu (Children) Hospital, Dhaka. Cell: 01711535148, E-mail: manzoor-hussain@hotmail.com 
infants treatment frequently includes aggressive support of cardiac function and perfusion, with volume and inotropic agents to enhance cardiac output and systemic $\mathrm{O}_{2}$ transport. Oxygen is well known as a pulmonary vasodilator and should be started at $100 \% .{ }^{12}$ Primary treatment of the neonate depends on the underlying disorder. A variety of treatment options includes surfactant, sedation, alkalinization, vasodilatation (e.g., inhaled nitric oxide, prostaglandin, milrinone, magnesium sulfate, adenosine, bosentan, sildenafil) and extracorporeal membrane oxygenation (ECMO). ${ }^{13}$ Ventilation is crucial for PPHN treatment since it facilitates alveolar recruitment and lung expansion, improving ventilation/perfusion matching. ${ }^{14}$ High frequency oscillatory ventilation may be useful in the management of infants who are being considered for treatment with extracorporeal membrane oxygenation (ECMO). ${ }^{12}$ The combined use of inhaled nitric oxide (iNO) and high occupancy vehicle (HFOV) has been demonstrated to be more successful than use of iNO or HFOV alone. ${ }^{7}$

However, many developing countries and resource limited centers do not have the funds or the technical expertise required for these expensive therapies. ${ }^{15}$ Sildenafil is a potent and selective inhibitor of cGMPspecific phosphodiesterase 5 (PDE5). This isoenzyme metabolizes cGMP which is the second- messenger of NO and a principle mediator of smooth muscle relaxation and vasodilatation. By inhibiting the hydrolytic breakdown of cGMP, sildenafil prolongs the action of cGMP. This results in augmented smooth muscle relaxation and cause pulmonary vasodilatation. ${ }^{16}$ Sildenafil decreases pulmonary vascular resistance in pulmonary hypertensive neonate. ${ }^{17}$ Fatema et $\mathrm{al}^{18}$, Mamun et $\mathrm{l}^{19}$ and Wadud et $\mathrm{al}^{20}$ found that sildenafil is very effective in the treatment of PPHN among Bangladeshi neonate. So where nitric oxide facilities are not available, cheap alternative like sildenafil for first line treatment of PPHN Can be effectively used.

\section{Conclusion}

PPHN is a devastating disease affecting neonates with high mortality and morbidity. Resource limited centers do not have the funds or the technical expertise required for these expensive therapies. Proper identification along with alternative and less expensive treatment leads to better outcome in PPHN in countries with limited resources.

\section{References}

1. Walsh-Sukys MC, Tyson JE, Wright LL, Bauer CR, Korones SB, Stevenson DK, et al. Persistent pulmonary hypertension of the newborn in the era before nitric oxide: Practice variation and outcomes. Pediatrics 2000;105:14-20.

2. Askin DF. Fetal-to-neonatal transition- what is normal and what is not? Neonatal Netw 2009;28: e3340.

3. Dhillon R. The management of neonatal pulmonary hypertension. Arch Dis Child Fetal Neonatal Ed 2012;97:F223-F228.

4. Steinhorn RH. Neonatal pulmonary hypertension. Pediatr Crit Care Med 2010;11 Suppl:S79-S84.

5. Van Marter LJ, Hernandez-Diaz S, Werler MM. Nonsteroidal anti-inflammatory drugs in late pregnancy and persistent pulmonary hypertension of the newborn. Pediatrics 2013;131:79-87.

6. Konduri GG, Kim UO. Advances in the diagnosis and management of persistent pulmonary hypertension of the newborn. Pediatr Clin North Am 2009;56:579600 .

7. Anne G, Anthony D. Pulmonary disease of the newborn. In: Rennie JM, editor. Roberton's Textbook of Neonatology. 4th ed. Philadelphia: Elsevier; 2005. p.496-502.

8. Sharma M. Approach to a cyanotic neonate. In: Raju U, Mathai SS, editor. Manual of NICU Protocols. 1st ed. Pune: Dept of Pediatrics, AFMC; 2007. p.83-91.

9. Roberta AB, Thomas NH, Anthony C. Respiratory failure in the infant. In: William HT, Ballard RA,Christine AG, editors. Avery's Disease of the Newborn 8th ed. Philadelphia: Elsevier Saunders; 2005. p.705-12.

10. Dudell GG, Stoll BJ. Respiratory tract disorders. In: Kliegman RM, Behrman RE, Jenson HB, Stanton BF, editors. Nelson Textbook of Pediatrics. 18th ed. Philadelphia: Elsevier Saunders; 2007. p.744-46.

11. Kinsella JP, Abman SH. Inhaled nitric oxide therapy in children. Paediatr Respir Rev 2005;6:190-98.

12. Gao Y, Raj JU. Regulation of the pulmonary circulation in the fetus and newborn. Physiol Rev 2010;90:1291-1335. 
13. Konduri GG, Kim UO. Advances in the diagnosis and management of persistent pulmonary hypertension of the newborn. Pediatr Clin North Am 2009;56:579600 .

14. Rocha G, Baptista MJ, Guimaraes H. Persistent pulmonary hypertension of non cardiac cause in a neonatal intensive care unit. Pulm Med 2012; doi:10.1155/2012/818971.

15. Chambers CD, Hernandez-Diaz S, Van Marter LJ, Werler MM, Louik C, Jones KL, et al. Selective serotonin-reuptake inhibitors and risk of persistent pulmonary hypertension of the newborn. $N$ Engl $J$ Med 2006;354:579-87.

16. Reffelmann T, Kloner RA. Therapeutic potential of phosphodiesterase 5 inhibition for cardiovascular disease. Circulation 2003;108:239-44.
17. Humbert M, Sitbon O, Simonneau G. Treatment of pulmonary arterial hypertension. $N$ Engl J Med 2004;351:1425-36.

18. Fatema NN. Persistent Pulmonary Hypertension of Newborn: Analysis of 181 cases over one year. Cardiovascular Journal 2018; 11: 17-22.

19. Mamun MAA, Hussain M, Jabbar A. Magnesium Sulphate Versus Sildenafil in the Treatment of Persistent Pulmonary Hypertension of Newborn: A Randomized Clinical Trial. Journal of Science and Technology Research 2016-2017 2018;1:80-85.

20. Wadud A. Sildenafil versus bosentan in the treatment of persistent pulmonary hypertension of newborn. MD Thesis. Bangladesh Institute of Child Health. University of Dhaka 2017. 
DS (Child) H J 2019; 35 (2) 